\title{
STRUCTURE OF THALISOPIDINE
}

Kh. G. Pulatova, Z. F. Ismailov, and S. Yu. Yunusov

Khimiya Prirodnykh Soedinenii, Vol. 5, No. 6, p. 609, 1969

UDC $547.944 / 945$

The isolation of the new alkaloid thalisopidine (I), $\mathrm{C}_{37} \mathrm{H}_{40} \mathrm{~N}_{2} \mathrm{O}_{l}$, a bisbenzyltetrahydroisoquinoline base, from the roots of Thalictrum isopyroides C. A. M. has been reported previously [1].

The methylation of thalisopidine (I) gave a O, O-dimethyl ether, mol. wt. 652 (mass spectrometry). The formation of the latter shows the presence of two hydroxyl groups in substance I.

The NMR spectrum of I, taken on a JNM-4H-100/100 MHz instrument ( $\tau$ scale) has signals at 7.56 and 7.51 ppm, each of three proton units, due to the protons of two $\mathrm{N}$-methyl groups. The signals of the protons of three methoxyl groups appear in the form of three singlets: at $7.04,6.70$, and $6.30 \mathrm{ppm}$. The NMR spectrum of thalisopidine (I) is very similar to that of thalisopine (II) (table).

NMR Spectra

\begin{tabular}{l|c|c|c|c|c|c|c}
\hline \multirow{2}{*}{ Alkaloid } & \multicolumn{2}{|c|}{$\mathrm{N}-\mathrm{CH}_{3}$} & \multicolumn{3}{|c|}{$\mathrm{O}-\mathrm{CH}_{3}$} & $\mathrm{H}_{\text {arom. }}$ \\
\cline { 2 - 7 } & 2 & $2^{\prime}$ & 6 & $6^{\prime}$ & 7 & $4^{*}$ & $8^{\prime}$ \\
\hline $\begin{array}{l}\text { Thalisapidine } \\
\text { Thalisopine }\end{array}$ & 7.51 & 7.56 & 6.30 & 6.70 & 7.04 & - & 3.70 \\
7.52 & 7.57 & 6.30 & 6.71 & 7.00 & 6.14 & 3.69
\end{tabular}

A comparison of the spectra of I and II showed that the spectrum of thalisopidine (I) lacks the signal of the protons of a methoxyl group in position $4^{n}$. Consequently, the second hydroxyl group in I occupies the C-4" position. The presence of a hydroxyl group at $\mathrm{C}-4^{\prime \prime}$ is confirmed by its clear phenolic nature, and also by a positive Million reaction [2].

On the basis of these facts, structure I is proposed as the most probable for thalisopidine.

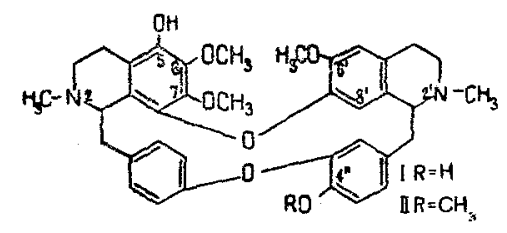

\section{REFERENCES}

1. Kh. G. Pulatova, S. Kh. Maekh, Z. F. Ismailov, and S. Yu. Yunusov, KhPS [Chemistry of Natural Compounds], 4, 394, 1968.

2. H. King, J. Chem. Soc., 1472, 1937; 737, 1940.

7 July 1969

Institute of the Chemistry of Plant Substances AS UzSSR 